\title{
Plasmodium falciparum histidine rich protein 2 (pfhrp2): an additional genetic marker suitable for anti-malarial drug efficacy trials
}

\author{
Wahib M. Atroosh ${ }^{1,2^{*}}$ (1), Yee-Ling Lau', Georges Snounou ${ }^{3}$, Meram Azzani ${ }^{4}$ and Hesham M. Al-Mekhlafi,5,6
}

\begin{abstract}
Background: Genotyping of the three Plasmodium falciparum polymorphic genes, msp 1, msp2 and glurp, has been adopted as a standard strategy to distinguish recrudescence from new infection in drug efficacy clinical trials. However, the suitability of a particular gene is compromised in areas where its allelic variants distribution is significantly skewed, a phenomenon that might occur in isolated parasite populations or in areas of very low transmission. Moreover, observation of amplification bias has diminished the value of glurp as a marker.
\end{abstract}

Methods: The suitability of the polymorphic P. falciparum histidine-rich protein 2 (pfhrp2) gene was assessed to serve as an alternative marker using a PCR-sequencing or a PCR-RFLP protocol for genotyping of samples in drug efficacy clinical trials. The value of pfhrp2 was validated by side-by-side analyses of 5 admission-recrudescence sample pairs from Yemeni malaria patients.

Results: The outcome of the single pfhrp2 gene discrimination analysis has been found consistent with msp 1, msp2 and glurp pool genotyping analysis for the differentiation of recrudescence from new infection.

Conclusion: The findings suggest that under the appropriate circumstances, pfhrp2 can serve as an additional molecular marker for monitoring anti-malarials efficacy. However, its use is restricted to endemic areas where only a minority of $P$. falciparum parasites lack the pfhrp2 gene.

Keywords: Malaria, Plasmodium falciparum, Drug efficacy clinical trial, hrp2, msp1, msp2, Glurp

\section{Background}

Malaria drug efficacy clinical trials are conducted to monitor the continued efficacy of front-line anti-malarial drugs, particularly against falciparum malaria. After administration of full-dose malaria treatment, in vivo drug efficacy is assessed through clinical and parasitological follow-up according to standard protocols [1]. The erstwhile recommended follow-up duration of 14 days was revised to a standard 28 days that can be extended to 42 days or to 63 days for the drugs with a long half-life

*Correspondence: wahib_atrosh@yahoo.com

${ }^{1}$ Department of Parasitology, Faculty of Medicine, Universiti Malaya, 50603 Kuala Lumpur, Malaysia

Full list of author information is available at the end of the article
$[1,2]$. Given the short incubation period of $P$. falciparum, longer follow-up periods increase the likelihood of acquiring new infections, especially in areas of high malaria transmission, which can lead to an underestimate of drug efficacy through mistaken classification of newly acquired infections as drug failures. In order to counter this, molecular genotyping strategies based on polymerase chain reaction (PCR) amplification have been developed to correct estimates of drug efficacy in clinical trials by enabling a distinction between recrudescences versus new infections during the follow-up [3]. The genetic markers recommended by the World Health Organization (WHO) for PCR correction are the polymorphic regions of three $P$. falciparum genes: merozoite surface protein 1 ( $m s p 1$, block2), merozoite surface protein 2 original author(s) and the source, provide a link to the Creative Commons licence, and indicate if changes were made. The images or other third party material in this article are included in the article's Creative Commons licence, unless indicated otherwise in a credit line to the material. If material is not included in the article's Creative Commons licence and your intended use is not permitted by statutory regulation or exceeds the permitted use, you will need to obtain permission directly from the copyright holder. To view a copy of this licence, visit http://creativecommons.org/licenses/by/4.0/. The Creative Commons Public Domain Dedication waiver (http://creativeco mmons.org/publicdomain/zero/1.0/) applies to the data made available in this article, unless otherwise stated in a credit line to the data. 
(msp2, block3), and the repeat region 2 of the glutamaterich protein (glurp) [4]. The amplified allelic variants are classified according to size, and also to allelic type for the msp1 and msp2 [4].

The suitability of each marker depends on the local parasite population to comprise numerous allelic variants with an unbiased distribution. This is likely in areas of high transmission intensity where parasites are genetically diverse and infections are often polyclonal, with a multiplicity of infection (MOI) often reaching 5 , but less so in areas of low transmission with low MOI (1-2), where re-infections by the same genotype might occur more frequently. Furthermore, recent investigations showed that glurp genotyping is affected by amplification bias, thereby diminishing confidence in this marker for PCR correction strategies [5, 6]. Reliance on two genetic markers, as compared to three, will diminish the accuracy of PCR correction, and might lead to an overestimation of drug failures, which could prompt an unnecessary change of the first-line treatment, that is advocated when PCR-corrected failure rates exceed $10 \%[1,6,7]$.

Defined polymorphic microsatellite markers, that vary by the number of repeated short nucleotide sequences, have been used as an alternative or as an additional standard genotyping marker [8-11]. Microsatellite markers are usually located in non-coding regions and are considered to be selectively neutral. However, they are known for their instability, with the frequency of repeats within some loci capable of changing during the infection $[2,10]$, which might lead to underestimate drug failure rates $[2,10,12]$. Moreover, microsatellite markers require a range of 6-13 PCR reactions, based on the number of loci included in the analysis $[8,13,14]$ (Table 1 ).

The suitability of another polymorphic gene, coding for the $P$. falciparum histidine-rich protein 2 (pfhrp2), was assessed as an additional marker for the discrimination between recrudescent and new infections. Two genotyping protocols were designed and evaluated, PCR amplification followed by sequencing, and PCR followed by

Table 1 Comparison of pfhrp2 genotyping protocol with those of other markers generally used in drug efficacy trial

\begin{tabular}{llll}
\hline Protocol difference & phhrp2 & msp1+msp2 & Microsatellites \\
\hline Molecular protocol & $\begin{array}{l}\text { Single-run PCR } \\
\text { or }\end{array}$ & Nested PCR & Nested PCR \\
& PCR-RFLP & & \\
Sequencing & Yes** & No & No \\
Restriction enzyme & Yes*** & No & No \\
No. of PCR reaction & 1 & 7 & $6^{*}$ \\
Number of primers & 2 & 14 & $10-12^{*}$ \\
\hline
\end{tabular}

*Minimum for 5 loci, **For PCR-Sequencing protocol option, ***For PCR-RFLP protocol option restriction enzyme length polymorphism (PCR-RELP) analysis.

\section{Methods}

Study setting

In an in vivo study that aimed to assess the efficacy of artemisinin + sulfadoxine-pyrimethamine (AS-SP) drug combination against uncomplicated falciparum malaria in the Tehama region of Yemen [15], recurrent parasitaemia during follow-up was detected in five cases. Of these cases, three were classified as true recrudescence as they were found to carry the same malaria genotypes using the $m s p 1, m s p 2$ and glurp markers. During this study, the impact of pfhrp2 gene variation on the performance of hrp2-based RDT was evaluated in this area. Sequencing analysis revealed high genetic diversity for pfhrp 2 with notably low allelic variant frequency distribution [16].

\section{Malaria isolates}

Five archived filter paper blood spot admission (prior to treatment baseline, or day 0 ) and recurrence (day X after ACT administration) sample pairs of $P$. falciparum infection were included in this analysis. During the 28 days of follow-up: one case recurred at day 14, two at day 21 and two others at day 28.

\section{DNA extraction}

Two to three discs (6 mm diameter) of the collected filter paper blood spot were utilized for genomic DNA extraction using Qiagen blood and tissue kit (QIAGEN, DNeasy $^{\circledR}$ Blood \& Tissue Kit, Germany). The DNA was eluted in $35 \mu \mathrm{L}$ AE elution buffer $(10 \mathrm{mM}$ Tris-Cl; $0.5 \mathrm{mM}$ EDTA; $\mathrm{pH} 9.0$ ) and stored at $-20^{\circ} \mathrm{C}$ until use.

\section{PCR amplification and sequencing analysis of pfhrp2}

Amplification of pfhrp 2 was carried out in a singlerun PCR using a specifically designed oligonucleotide primer pair (PfHRP2-F: 5'-TGTGTAGCAAAAATGCAA AAGG-3' ${ }^{\prime}$ and PfHRP2-R: $5^{\prime}$ TTAATGGCGTAGGCA ATGTG-3') flanking the polymorphic exon-2 region of the pfhrp 2 gene, as previously described [16]. Briefly, $3 \mu \mathrm{L}$ of the genomic DNA was added to total up $50 \mu \mathrm{L}$ reaction volume containing $20 \mu \mathrm{L}$ ExPrime Taq Premix (Genet Bio, Korea) and $2 \mu \mathrm{L}$ of each forward and reverse primers $(10 \mu \mathrm{M})$. Thermal cycling condition was initiated with a denaturation cycle at $95{ }^{\circ} \mathrm{C}$ for 5 min followed by 40 cycles (denaturation step at $95^{\circ} \mathrm{C}$ for $30 \mathrm{~s}$, annealing at $57{ }^{\circ} \mathrm{C}$ for $40 \mathrm{~s}$ and an extension step at $72{ }^{\circ} \mathrm{C}$ for $90 \mathrm{~s}$ ) and a final extension cycle at $72{ }^{\circ} \mathrm{C}$ for $10 \mathrm{~min}$. All amplification reactions were performed using $\mathrm{MyCycler}^{\mathrm{TM}}$ or T100 Thermal Cyclers (BioRad, Hercules, USA). The PCR products were visualized in $2 \%$ agarose gel pre-stained with $\mathrm{Sybr}^{\circledR}$ safe DNA gel stain (Invitrogen, USA) using a 
gel-documenting system (Bio-Rad, Hercules, CA, USA). Amplicon lengths in base pair were reported against 100 DNA ladder [16].

The PCR product bands were cut out of the gels, purified, and sequenced in both directions. The corresponding consensus amino acid sequences were aligned using BioEdit Sequence Alignment Editor Software (version 7.1.9) and Molecular Evolutionary Genetics Analysis (Mega) software (version 7.0.26) and analysed for the type and number of amino acid repeat units [16]. The sequences for the sample pairs (day 0 sample and day $\mathrm{X}$ ) from this study were aligned and analysed for similarity in the type and number of the amino acid repeat units. A day $\mathrm{X}$ sample was classified as true recrudescent (treatment failure) if it showed $100 \%$ similarity in the amino acid repeat type and number as compared to that from the day 0 baseline sample. A difference in the type and/ or in the number of one or more of the amino acid repeat units led the sample to be classed as a new infection.

\section{PCR-RFLP analysis of pfhrp2}

Given that sequencing might not be readily available in some settings, a genotyping protocol based on restriction enzyme length polymorphism (RFLP) analysis of the amplified fragment was designed and evaluated. Each PCR product was subjected to digestion using one of two restriction enzymes: Alu I (cutting site AGCT) and Pvu II (cutting site CAGCTG). Post-digestion products were then analysed in $2.5 \%$ agarose gels and the number and size of fragments reported for each sample. Identical digestion patterns between day 0 and day X paired samples indicated a treatment failure, while a difference indicated a new infection.

\section{msp1, msp2 and glurp genotyping}

Amplification and analyses of $m s p 1, m s p 2$ and glurp genes were performed using nested PCR according to previously described standard protocols $[3,4,17]$. Amplicons were visualized in $2.5 \%$ agarose gel stained with Sybr $^{\circledR}$ safe DNA gel stain (Invitrogen, USA) using UV documenting system (Bio-Rad, Hercules, CA, USA). The size of the PCR products for each marker was reported and then grouped into different size bins of $25 \mathrm{bp}$ for $m s p 1$ and $m s p 2$, and $50 \mathrm{bp}$ for glurp. For the recurrent parasitaemia during the in vivo follow-up period, samples of both day 0 (i.e., pre-treatment) and their corresponding samples collected at day X (i.e. post-treatment) were genotyped and compared for alleles similarities.

\section{Determining allelic frequency distribution for pfhrp2}

The type and frequency of the $p f h r p 2$ alleles in the study area were derived using the $p f h r p 2$ sequence of 180 samples obtained from the previous study [16]. A difference of one amino acid or more was considered sufficient to define a new allelic type, and allelic frequencies were then calculated.

\section{Determining allelic frequency distributions for $\mathrm{msp} 1, \mathrm{msp} 2$ and glurp}

At least fifty samples are recommended to estimate the allelic frequency and the multiplicity of infection (MOI) of the msp1, msp2 allelic families and glurp genotypes [1]. Thus, fifty archived blood samples of $P$. falciparum mono-infection were randomly selected and genotyped as previously described [17]. A representative size fragment for each msp1 allelic family (K1, MAD 20 and RO33) and $m s p 2$ allelic family (3D7/IC and FC27), as well as glurp allelic variants, were subjected to sequencing to confirm the nature of the allelic variants.

\section{Results}

Distribution of msp1, msp2 and glurp alleles

Out of the fifty randomly selected samples, 46 were successfully amplified for all three markers: msp1, msp2 and glurp. Six allelic variants were observed for $m s p 1$, five for the $m s p 2$ and five for glurp. The frequencies of the 200-225 bp MAD20, and 150 bp RO33 msp1 allelic variants, and the 350-400 bp FC27 and 600-650 bp 3D7/ IC $m s p 2$ allelic variants were biased as they were found in $32.5 \%, 25 \%, 28 \%$ and $39.7 \%$ of the examined samples, respectively. Similarly, the glurp alleles $900-1000$ and 1000-1100 bp allelic variants were predominant with frequencies of $32.6 \%$, and $30.5 \%$, respectively. Therefore, distinguishing recrudescence from new infection in this area using these alleles might be challenging. Nonetheless, the other 10 allelic variants of $m s p 1, m s p 2$ and glurp had low frequencies (3.8-15\%) (Fig. 1). The MOI of the P. falciparum isolates analysed was 1.7, 1.5 and 1.0 for msp1, msp2 and glurp, respectively. Thus, the validity of these three markers for PCR correction was sub-optimal, and likely to over-estimate treatment failures.

\section{Diversity and frequency distribution of the pfhrp2 alleles} In a previous survey of $p f h r p 2$ gene variation [16] conducted in the same area, all isolates (189) were successfully amplified (100\% amplification rate) and the pfhrp 2 fragment obtained successfully sequenced. The isolates were all found to carry a single allelic variant (i.e., MOI $=1$ ).

Analyses of these pfhrp 2 sequences showed a high degree of genetic diversity with 46 distinct allelic variants (477-969 bp, corresponding to 159-323 amino acids) found circulating in the area. Of these, 45 alleles $(97.8 \%)$ occurred in very low frequency $(<5 \%)$, though 

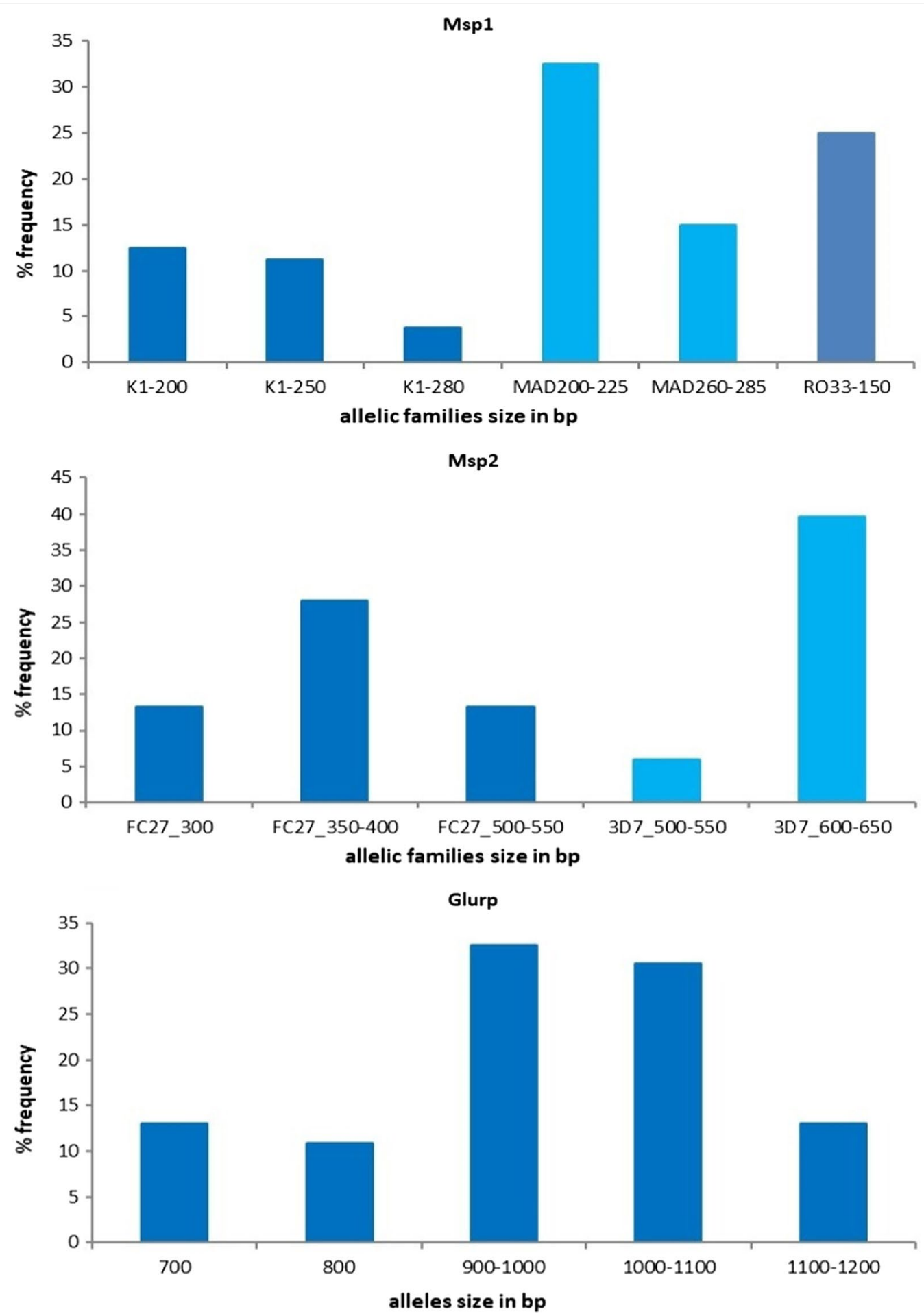

Fig. 1 Distribution of the P. falciparum msp1, msp2 and glurp markers allelic variants in 46 isolates from the Tehama region, Yemen 


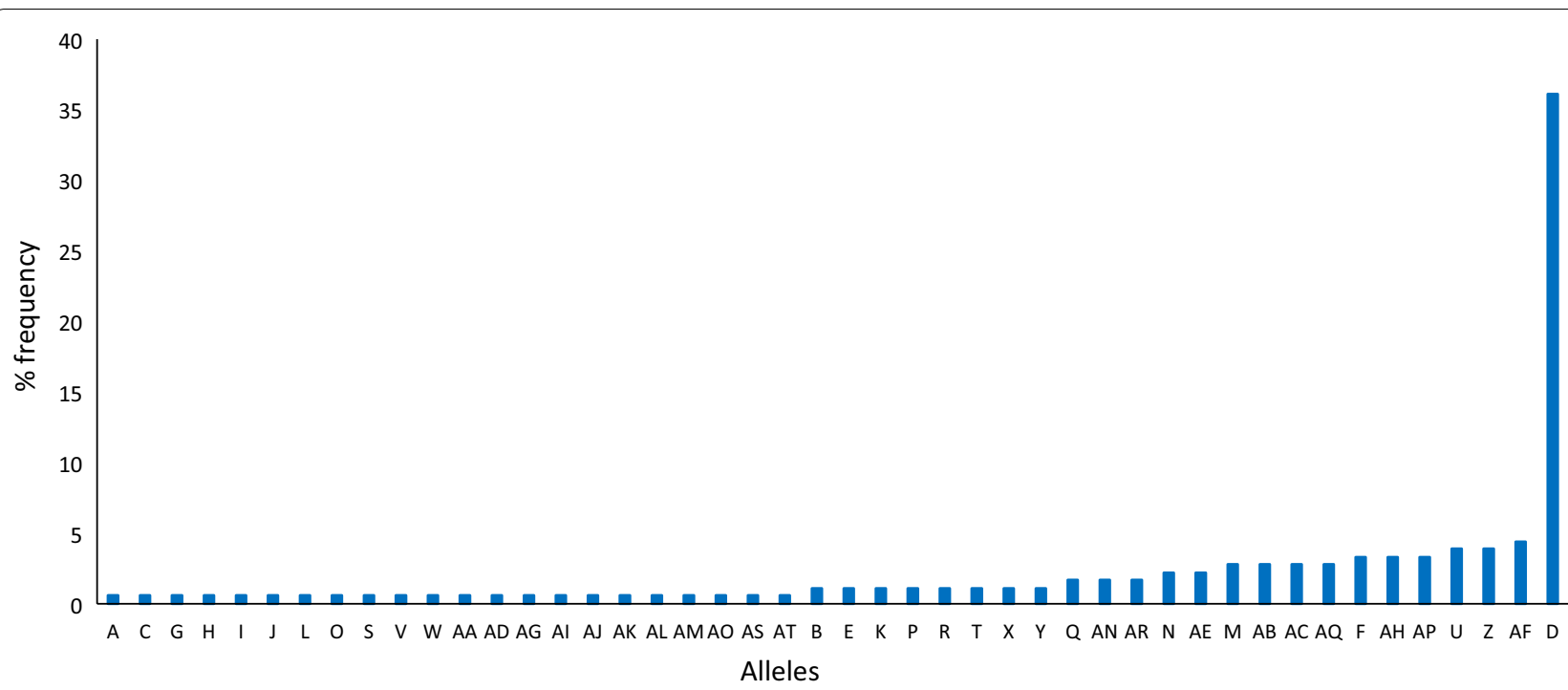

Fig. 2 Distribution of the P. falciparum hrp2 marker allelic variants in 180 isolates from the Tehama region, Yemen

one (540 bp) was dominant as it was found in 65 of the 180 analysed samples (36.1\%) (Fig. 2). Details of the hrp2 allelic variants classification are provided in Additional file 1 .

\section{PCR correction of recurrent cases based on pfhrp2 as a genotyping marker}

Analysis of the paired samples from the five cases with recurrent parasitaemia was conducted by $p$ fhrp 2 amplification followed by sequencing. Comparison of the amino acid type repeats and their frequency in the baseline (day 0 ) and day $X$ sample pairs, indicated that the outcome for two of the patients could be classed as a re-infection (case 2 and case 5), while the other three cases could be classed as recrudescences, i.e., treatment failures (Fig. 3). These results were entirely consistent with the PCR correction that was carried out previously using the standard $m s p 1$, msp 2 and glurp markers (Table 2) [15].

Two restriction enzymes, Alu I or $P v u$ II, have been selected for RFLP analysis, and the digests of the amplified $p f h r p 2$ fragments from the paired samples from the five cases were compared in order to reveal potential differences between allelic variants without the need for sequencing. The presence of an identical number and size of the resulting bands derived from the day 0 and day $\mathrm{X}$ sample pairs indicated a recrudescence (cases 1, 3 and 4), while distinct patterns for the paired samples indicated a re-infection (cases 2 and 5) (Fig. 4A and $\mathrm{B}$ ). These results were consistent with those based on genotyping based on the analysis of the pfhrp2 repeats sequences as well as that based on the standard $m s p 1, m s p 2$ and glurp genotyping protocols.

\section{Discussion}

Malaria drug efficacy clinical trial in endemic areas remains the gold standard method for monitoring changes in the efficacy of antimalarial drugs, and their outcomes guide the treatment policy adopted nationally. Correction of these outcomes via parasites genotyping, in which treatment failures are distinguished from re-infections that might have arisen during the follow-up period, has substantially improved outcome accuracy. In recent years, three genetic markers with standardised genotyping protocols have been adopted [1] in order to ensure consistency and comparability between studies. The validity of one of these markers ( lurp) has been recently put into question [5], and in some regions low allelic diversity for the one or other of the other two markers (msp1 and msp2) diminishes their adequacy [18-20]. The likelihood of low genetic diversity increases in areas of low transmission intensity or in those where anti-malarial measures are leading to near elimination. In such cases, additional polymorphic genetic markers will need to be considered to achieve PCR correction of trial outcomes.

Given the very high diversity observed for the variable repeat region of the pfhrp 2 exon in many malaria endemic areas [21, 22], including those with low transmission intensity, its usefulness was assessed as a potential additional genetic marker for PCR correction analyses. Although amplicon size could be sufficient to discriminate between two isolates, two post-amplification strategies with a higher resolution were employed to distinguish between the various allelic variants: amplicon sequencing, an onerous though highly accurate method, and RFLP analysis, a less sensitive but more field-friendly approach. In the present study, the potential of $p f h r p 2$ as an 

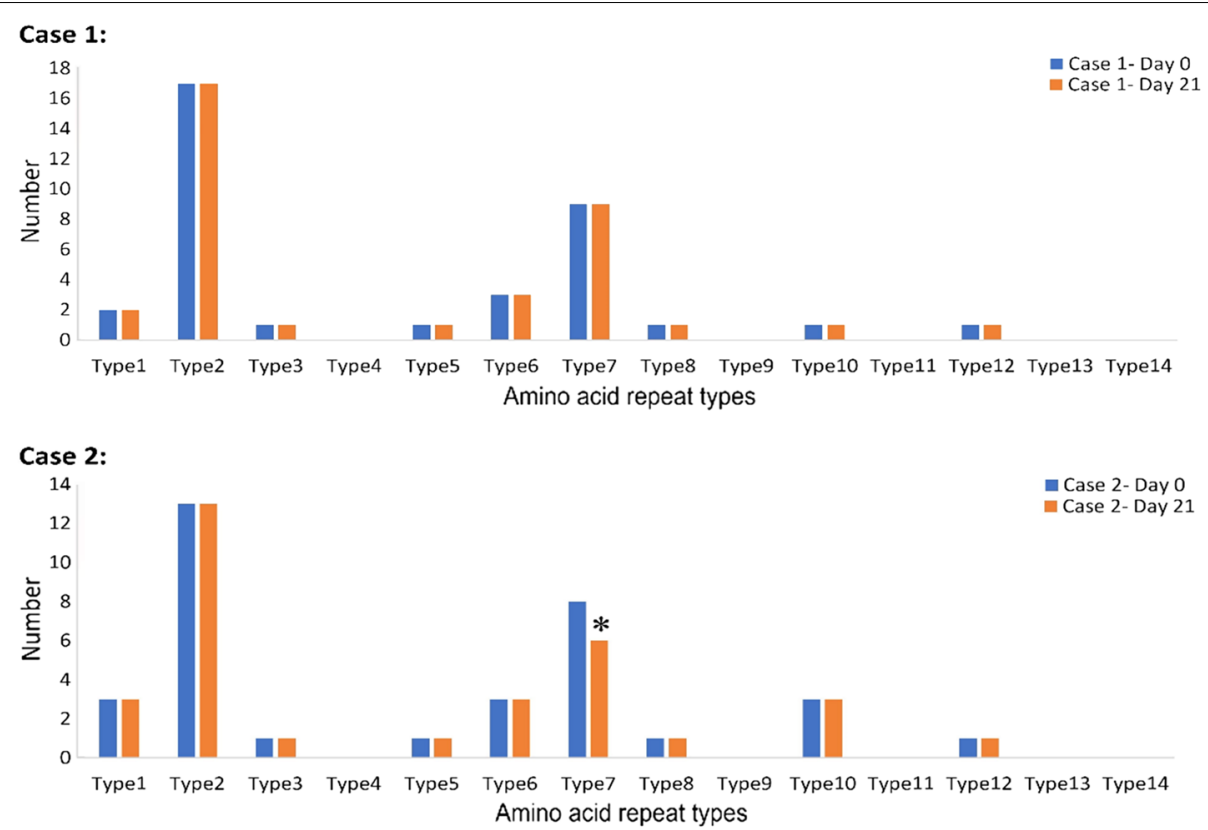

Case 3:

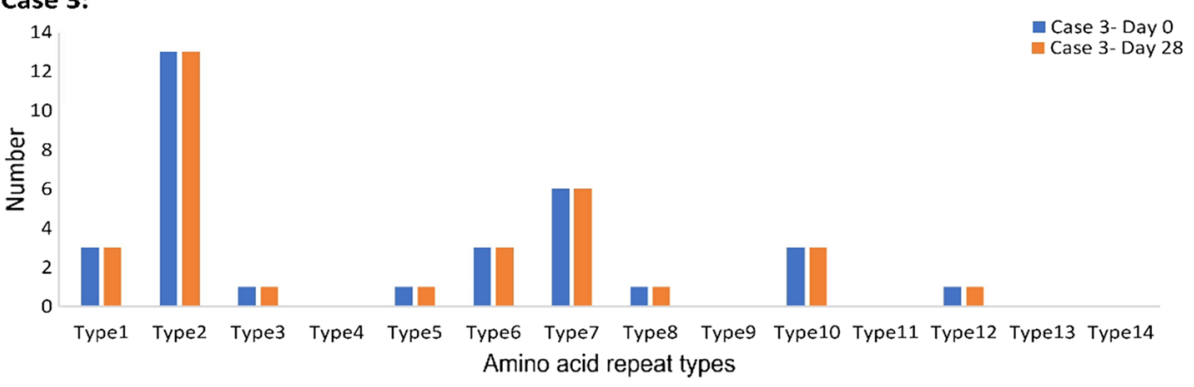

Case 4:

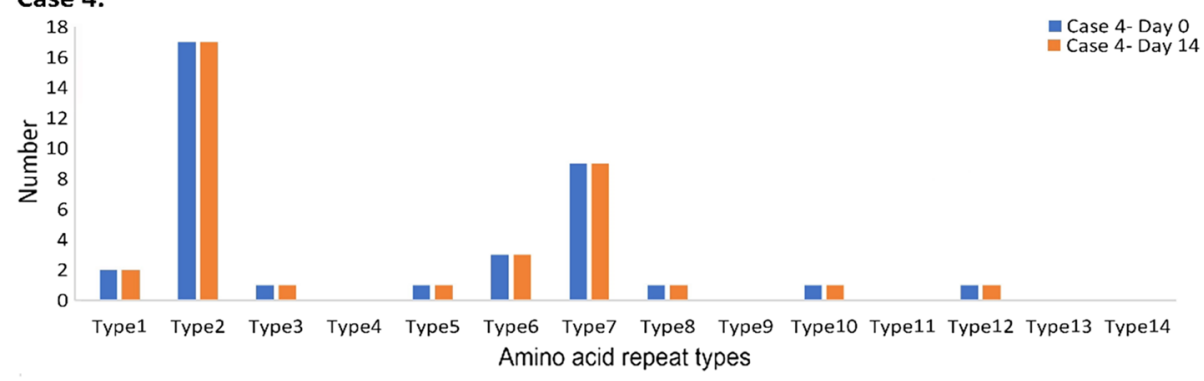

Case 5:

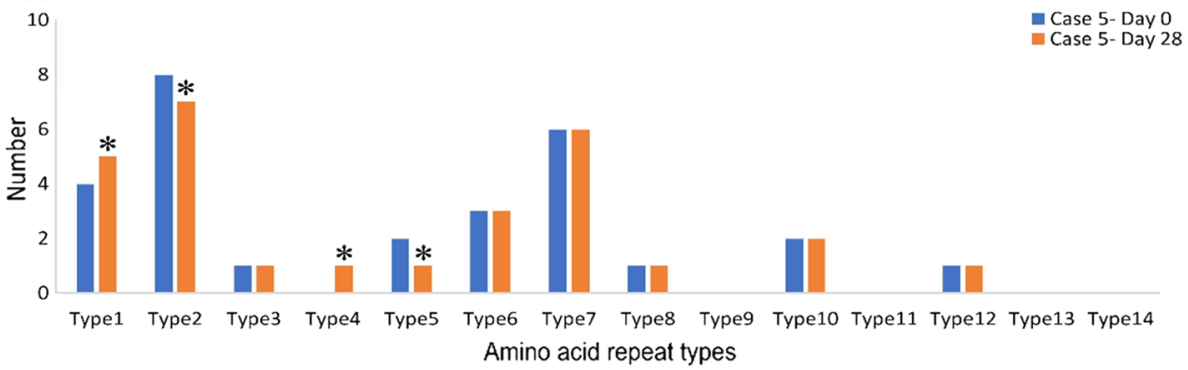

Fig. 3 Types and numbers of pfhrp2 amino acid repeat units for distinguishing between cases of recrudescent or re-infection from a clinical trial in Tehama region, Yemen. * Difference in occurrence, type, or number of amino acid repeat units 
Table 2 Discrimination of recrudescent from new infection episodes from cases in the drug efficacy trial in the Tehama region, Yemen based on msp1, msp2 and glurp genotyping

\begin{tabular}{|c|c|c|c|c|c|c|c|}
\hline \multirow[t]{2}{*}{ Case } & \multicolumn{3}{|c|}{ Msp1 } & \multicolumn{2}{|l|}{ Msp2 } & \multirow[t]{2}{*}{ Glurp } & \multirow[t]{2}{*}{ Outcome } \\
\hline & K1 & MAD20 & RO33 & FC27 & IC & & \\
\hline \multicolumn{8}{|l|}{ Case 1} \\
\hline Day-0 & 180 & - & - & 300 & - & 1000 & RECRUDESCENCE \\
\hline Day-21 & 180 & - & - & 300 & - & 1000 & \\
\hline \multicolumn{8}{|l|}{ Case $2^{*}$} \\
\hline Day-0 & - & - & 150 & 450 & - & 900 & NEW INFECTION \\
\hline Day-21 & 200 & - & - & - & 500 & 1000 & \\
\hline \multicolumn{8}{|l|}{ Case 3} \\
\hline Day-0 & 180 & - & - & - & 500 & 1000 & RECRUDESCENCE \\
\hline Day-28 & 180 & - & - & - & 500 & 1000 & \\
\hline \multicolumn{8}{|l|}{ Case 4} \\
\hline Day-0 & 180 & - & 150 & 300 & 600 & 900 & RECRUDESCENCE \\
\hline Day-14 & 180 & - & 150 & 300 & 600 & 900 & \\
\hline \multicolumn{8}{|l|}{ Case $5^{*}$} \\
\hline Day-0 & 200 & - & - & 350 & - & 900 & NEW INFECTION \\
\hline Day-28 & - & 230 & - & 280 & - & 900 & \\
\hline
\end{tabular}

*Cases for which the D0/DX samples genotyping patterns differed are presented in bold
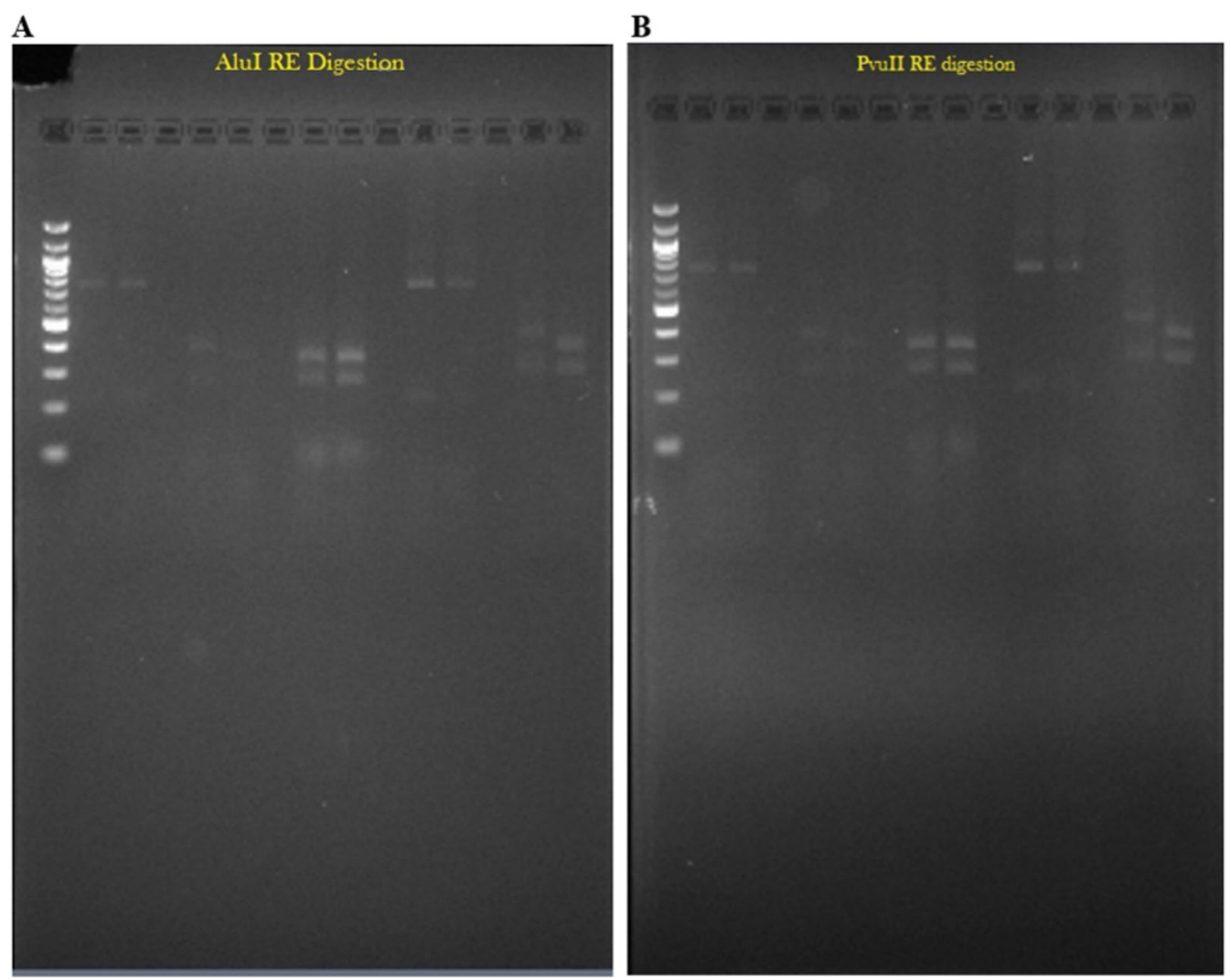

Fig. 4 Digestion pattern of pfhrp2 PCR products using A $P v u$ II, and $\mathbf{B}$ Alu I restriction enzymes. Lane 1: 100 bp DNA ladder, Lane 2: case 1, day 0; Lane 3: case 1, day 21, Lane 5: case 2, day 0; Lane 6: case 2, day 21, Lane 8: case 3, day 0; Lane 9: case 3, day 28, Lane 11: case 4, day 0; Lane 12: case 4, day 14, Lane 14: case 5, day 0, Lane 15: case 5, day 28 
additional marker for PCR correction analyses in Yemen has been demonstrated. Genotyping of the paired samples from the five cases with recurrent episodes confirmed the classification (recrudescence or re-infection) that was obtained using the three standard markers. Moreover, in this case, this was equally achieved by direct sequencing of the PCR product as well as through restriction enzymes digestion of the amplicons. It must be noted that this preliminary study concerned only 5 cases that were sampled about seven years ago. Therefore, validation of this marker will require further studies to confirm its usefulness.

Nevertheless, it must be stressed that the value of pfhrp 2 as a genotyping marker is severely compromised in areas where this gene is fully or partially deleted in a large proportion of the circulating parasites. Plasmodium falciparum parasites lacking pfhrp 2 were first noted in Peru, where $41 \%$ of the samples collected proved negative for this gene [23]. Similar observations were made in the following year with samples collected in various South American countries [24-29], though much lower proportions of such parasites were recorded in other areas at that time [30-32]. A recent systematic review on the prevalence of $p f h r p 2$ negative parasites indicated that their prevalence is highly variable and potentially equally focal [33]. Thus, pfhrp 2 must not be used as a maker for PCR correction in areas where the prevalence of the parasites lacking the exon 2 of this gene exceeds a few percentage points (10\% as a conservative suggestion). Nonetheless, given its high genetic diversity with allelic variants that can be distinguished by amplicon length, restriction digestions patterns and eventually sequencing, pfhrp 2 can serve as a first marker to be analysed from paired samples; any cases thereby clearly classed as re-infection could then be excluded from those that would require genotyping by the other markers ( $m s p 1$ and $m s p 2$ ), thus saving time and resources.

\section{Conclusion}

The polymorphic $p f h r p 2$ gene has the potential to act as an additional genetic marker for inclusion in the PCR genotyping protocols employed to correct the outcomes of in vivo efficacy drug trials conduction in malaria endemic areas. However, its use is restricted to endemic areas where only a very small minority of $P$. falciparum population lack the $p f h r p 2$ gene.

\section{Abbreviations}

ACT: Artemisinin-based combination therapy; msp 1: Merozoite surface protein 1; msp2: Merozoite surface protein 2; glurp: Glutamate-rich protein; pfhrp2: P. falciparum Histidine-rich protein 2; AS: Artemisinin; SP: Sulfadoxine-pyrimethamine.

\section{Supplementary Information}

The online version contains supplementary material available at https://doi. org/10.1186/s12936-021-04014-4.

Additional file 1. Description and classification of the pfhrp2 allelic variants classification and their frequencies.

\section{Acknowledgements}

The authors would like to thank the National Malaria Control Programme, Yemen (NMCP) staff for their generous cooperation and support. The authors are also grateful to all patients for their voluntarily participation in this study.

\section{Authors' contributions}

WMA and GS conceived and designed the experiments. WMA conducted the sampling, field survey and laboratory experiments. WMA, GS and HMA were involved in the interpretation of results. WMA and HMA analysed the data and wrote the first draft. GS, MA and LYL reviewed and revised the manuscript critically. All authors read and approved the final manuscript.

\section{Funding}

The work was funded by the Universiti Malaya High Impact Research Grant UM-MOHE (UM.C/625/1/HIR/MOHE/MED/16), the Ministry of Higher Education, Malaysia.

\section{Availability of data and materials}

The data that support the findings of this study are available from the corresponding author upon reasonable request.

\section{Declarations}

Ethics approval and consent to participate

This study was approved by the Medical Ethics Committee of the University of Malaya Medical Centre, Kuala Lumpur (Ref. 974.19), and by the Ministry of Health and the NMCP in Yemen. Written and signed informed consents were obtained from the patients prior to collecting blood samples.

\section{Consent for publication \\ Not applicable.}

\section{Competing interests}

The authors declare that they have no competing interests.

\section{Author details}

${ }^{1}$ Department of Parasitology, Faculty of Medicine, Universiti Malaya, 50603 Kuala Lumpur, Malaysia. ${ }^{2}$ Department of Microbiology and Parasitology, Faculty of Medicine and Health Sciences, University of Aden, Aden, Yemen. ${ }^{3}$ CEA-Université Paris Sud 11-INSERM U1184, Immunology of Viral Infections and Autoimmune Diseases (IMVA-HB), IDMIT Department, IBFJ, DRF, Fontenay-aux-Roses, France. ${ }^{4}$ Department of Community Medicine, Faculty of Medicine, MAHSA University, Bandar Saujana Putra, Selangor, Malaysia. ${ }^{5}$ Department of Parasitology, Faculty of Medicine and Health Sciences, Sana'a University, Sana'a, Yemen. ${ }^{6}$ Medical Research Centre, Jazan University, Jazan, Kingdom of Saudi Arabia.

Received: 17 September 2021 Accepted: 7 December 2021 Published online: 04 January 2022

References

1. WHO. Methods for surveillance of antimalarial drug efficacy. Geneva: World Health Organization, 2009. https://apps.who.int/iris/handle/10665/ 44048. Accessed 16 July 2021

2. Jones S, Kay K, Hodel E, Chy S, Mbituyumuremyi A, Uwimana A, et al. Improving methods for analyzing antimalarial drug efficacy trials: molecular correction based on length-polymorphic markers msp-1, msp2, and glurp. Antimicrob Agents Chemother. 2019;63:e00590-e619. 
3. Snounou G, Beck HP. The use of PCR genotyping in the assessment of recrudescence or reinfection after antimalarial drug treatment. Parasitol Today. 1998;14:462-7.

4. Medicines for Malaria Venture \& WHO. Methods and techniques for clinical trials on antimalarial drug efficacy: genotyping to identify parasite populations: informal consultation organized by the Medicines for Malaria Venture and cosponsored by the World Health Organization, 29-31 May 2007, Amsterdam, The Netherlands. World Health Organization, 2008. https://apps.who.int/iris/handle/10665/43824. Accessed 2 July 2021.

5. Messerli C, Hofmann NE, Beck HP, Felger I. Critical evaluation of molecular monitoring in malaria drug efficacy trials and pitfalls of length-polymorphic markers. Antimicrob Agents Chemother. 2017;61:e01500-e1516.

6. Felger I, Snounou G, Hastings I, Moehrle JJ, Beck HP. PCR correction strategies for malaria drug trials: updates and clarifications. Lancet Infect Dis. 2020;20:e20-5

7. WHO. Malaria surveillance, monitoring \& evaluation: a reference manual. Geneva: World Health Organization, 2018. https://www.who.int/publi cations/i/item/9789241565578. Accessed 20 July 2021.

8. Anderson TJC, Su XZ, Bockarie M, Lagog M, Day KP. Twelve microsatellite markers for characterization of Plasmodium falciparum from finger-prick blood samples. Parasitology. 1999;119:113-25.

9. Greenhouse B, Myrick A, Dokomajilar C, Woo JM, Carlson EJ, Rosenthal PJ, et al. Validation of microsatellite markers for use in genotyping polyclonal Plasmodium falciparum infections. Am J Trop Med Hyg. 2006;75:836-42.

10. Mwangi JM, Omar SA, Ranford-Cartwright LC. Comparison of microsatellite and antigen-coding loci for differentiating recrudescing Plasmodium falciparum infections from reinfections in Kenya. Int J Parasitol. 2006:36:329-36.

11. Nyachieo A, Van overmeir C, Laurent T, Dujardin JC, D'Alessandro U. Plasmodium falciparum genotyping by microsatellites as a method to distinguish between recrudescent and new infections. Am J Trop Med Hyg. 2005;73:210-3.

12. Zhong D, Lo E, Wang X, Yewhalaw D, Zhou G, Atieli HE, et al. Multiplicity and molecular epidemiology of Plasmodium vivax and Plasmodium falciparum infections in East Africa. Malar J. 2018;17:185

13. Gatei W, Gimnig JE, Hawley W, ter Kuile F, Odero C, Iriemenam NC, et al. Genetic diversity of Plasmodium falciparum parasite by microsatellite markers after scale-up of insecticide-treated bed nets in western Kenya. Malar J. 2015;14:495.

14. Nderu D, Kimani F, Karanja E, Thiong'o K, Akinyi M, Too E, et al. Genetic diversity and population structure of Plasmodium falciparum in KenyanUgandan border areas. Trop Med Int Health. 2019;24:647-56.

15. Atroosh WM, Al-Mekhlafi HM, Snounou G, Al-Jasari A, Sady H, Nasr NA et al. Sustained efficacy of artesunate-sulfadoxine-pyrimethamine against Plasmodium falciparum in Yemen and a renewed call for an adjunct single dose primaquine to clear gametocytes. Malar J. 2016;15:295.

16. Atroosh WM, Al-Mekhlafi HM, Al-Jasari A, Sady H, Al-Delaimy AK, Nasr NA, et al. Genetic variation of pfhrp2 in Plasmodium falciparum isolates from Yemen and the performance of HRP2-based malaria rapid diagnostic test. Parasit Vectors. 2015:8:388

17. Snounou G, Zhu X, Siripoon N, Jarra W, Thaithong S, Brown KN, et al. Biased distribution of $m s p 1$ and msp2 allelic variants in Plasmodium falciparum populations in Thailand. Trans R Soc Trop Med Hyg. 1999:93:369-74

18. Jiménez JN, Snounou G, Letourneur F, Rénia L, Vélez ID, Muskus CE. Near-fixation of a Pfmsp 1 block 2 allelic variant in genetically diverse Plasmodium falciparum populations across Western Colombia. Acta Trop. 2010;114:67-70

19. Al-Abd NM, Mahdy MAK, Al-Mekhlafi AMQ, Snounou G, Abdul-Majid NB, Al-Mekhlafi HM, et al. The suitability of $P$. falciparum merozoite surface proteins 1 and 2 as genetic markers for in-vivo drug trials in Yemen. PLoS One. 2013;8:e67853.

20. Alam MS, Elahi R, Mohon AN, Al-Amin HM, Kibria MG, Khan WA, Khanum $H$, Haque R. Plasmodium falciparum genetic diversity in Bangladesh does not suggest a hypoendemic population structure. Am J Trop Med Hyg. 2016;94:1245-50

21. Baker J, McCarthy J, Gatton M, Kyle DE, Belizario V, Luchavez J, et al. Genetic diversity of Plasmodium falciparum histidine-rich protein 2 (PfHRP2) and its effect on the performance of PfHRP2-based rapid diagnostic tests. J Infect Dis. 2005;192:870-7.
22. Gendrot M, Fawaz R, Dormoi J, Madamet M, Pradines B. Genetic diversity and deletion of Plasmodium falciparum histidine-rich protein 2 and 3: a threat to diagnosis of $P$. falciparum malaria. Clin Microbiol Infect. 2019;25:580-5.

23. Gamboa D, Ho MF, Bendezu J, Torres K, Chiodini PL, Barnwell JW, et al. A large proportion of $P$. falciparum isolates in the Amazon region of Peru lack PfHRP2 and PfHRP3: implications for malaria rapid diagnostic tests. PLoS ONE. 2010;5:e8091.

24. Maltha J, Gamboa D, Bendezu J, Sanchez L, Cnops L, Gillet P, et al. Rapid diagnostic tests for malaria diagnosis in the Peruvian Amazon: impact of pfhrp2 gene deletions and cross-reactions. PLoS ONE. 2012;7:e43094.

25. Akinyi S, Hayden T, Gamboa D, Torres K, Bendezu J, Abdallah J, et al. Multiple genetic origins of histidine-rich protein 2 gene deletion in Plasmodium falciparum parasites from Peru. Sci Rep. 2013;3:2797.

26. Murillo Solano C, Akinyi Okoth S, Abdallah JF, Pava Z, Dorado E, Incardona $\mathrm{S}$, et al. Deletion of Plasmodium falciparum histidine-rich protein 2 (pfhrp2) and histidine-rich protein 3 (pfhrp3) genes in Colombian parasites. PLoS ONE. 2015;10:e0131576.

27. Abdallah JF, Okoth SA, Fontecha GA, Torres REM, Banegas El, Matute ML, et al. Prevalence of pfhrp2 and pfhrp3 gene deletions in Puerto Lempira. Honduras Malar J. 2015;14:19.

28. Akinyi Okoth S, Abdallah JF, Ceron N, Adhin MR, Chandrabose J, Krishnalall K, et al. Variation in Plasmodium falciparum histidine-rich protein 2 (Pfhrp2) and Plasmodium falciparum histidine-rich protein 3 (Pfhrp3) gene deletions in Guyana and Suriname. PLoS One. 2015;10:e0126805.

29. Houze S, Hubert V, Le Pessec G, Le Bras J, Clain J. Combined deletions of pfhrp2 and pfhrp3 genes results in Plasmodium falciparum malaria falsenegative rapid diagnostic test. J Clin Microbiol. 2011;49:2694-6.

30. Koita OA, Doumbo OK, Ouattara A, Tall LK, Konaré A, Diakité M, et al. False-negative rapid diagnostic tests for malaria and deletion of the histidine-rich repeat region of the hrp2 gene. Am J Trop Med Hyg. 2012;86:194-8.

31. Kumar N, Pande V, Bhatt RM, Shah NK, Mishra N, Srivastava B, et al. Genetic deletion of HRP2 and HRP3 in Indian Plasmodium falciparum population and false negative malaria rapid diagnostic test. Acta Trop. 2013;125:119-21.

32. Bharti PK, Chandel HS, Ahmad A, Krishna S, Udhayakumar V, Singh N. Prevalence of pfhrp2 and/or pfhrp3 gene deletion in Plasmodium falciparum population in eight highly endemic states in India. PLoS One. 2016;11:e0157949.

33. Thomson R, Parr JB, Cheng Q, Chenet S, Perkins M, Cunningham J. Prevalence of Plasmodium falciparum lacking histidine-rich proteins 2 and 3: a systematic review. Bull World Health Organ. 2020;98:558-68.

\section{Publisher's Note}

Springer Nature remains neutral with regard to jurisdictional claims in published maps and institutional affiliations.

Ready to submit your research? Choose BMC and benefit from

- fast, convenient online submission

- thorough peer review by experienced researchers in your field

- rapid publication on acceptance

- support for research data, including large and complex data types

- gold Open Access which fosters wider collaboration and increased citations

- maximum visibility for your research: over $100 \mathrm{M}$ website views per year

At BMC, research is always in progress.

Learn more biomedcentral.com/submissions 